Published by the University of KwaZulu-Natal

https://journals.ukzn.ac.za/index.php/JICBE

(C) Creative Commons With Attribution (CC-BY)

Journal of Inclusive cities and Built environment. Vol. 2 Issue 1

How to cite: Dr Y.Luckan. 2022. Towards a Humanistic Approach to Inclusive Public Transport: A Critical Case Study of Durban, South Africa.

Conference Proceedings for International Symposium on Inclusive-Cities: Achieving Inclusive Cities Through A Multidisciplinary Approach, 2021 28-30 June. Journal of Inclusive cities and Built environment. Vol. 2 Issue 1, Pg 1-8.

\title{
TOWARDS A HUMANISTIC APPROACH TO INCLUSIVE PUBLIC TRANSPORT: A CRITICAL CASE STUDY OF DURBAN, SOUTH AFRICA
}

\author{
By Dr Y. Luckan
}

Published 31 January 2022

\section{ABSTRACT}

This paper argues that the core of the problem hinges on exclusive thinking and practice within disciplinary silos, disconnected from the multi-layered, subjective experience of urban place through movement in space and time. The problem that was traced back to the conceptual approaches to urban mobility.

KEY WORDS Mobility, Public Transport, Human Approach, Inclusive Durban 


\section{THE PROBLEM IN CONTEXT}

Durban, South Africa, is widely regarded as a socio-economically and culturally diverse modern city. While this diversity would be expected to translate into a vibrancy of place in the city, the reality is that vehicles dominate the city, confining people to congested sidewalks and a few pockets of public space such as squares and parks. While much thought has been expended on inclusive transport systems, these have largely been around the notion of mobility versus accessibility.

The OECD (2020) states: "A critical difference between mobility and accessibility planning stems from the fact that former focuses on improving transport networks performance while the latter aims at maximising the access to opportunities such as workplaces, services, entertainment, education, goods and culture, for instance" The problem with that definition, however, is that the concept of accessibility generally refers to measurable / quantifiable attributes, whereby the city would be primarily considered a place of access to social and economic opportunities or trade. While much thought is expended on the development of smart interchanges, the various overlaps of human interaction and experience do not form part of the definition of accessibility. The quantifiable attributes of inclusive cities have advanced wellness, to some extent, however holistic wellbeing has been neglected. Essentially, the objectivist approaches to urban mobility and accessibility have shifted the experience of city away from human conscious dwelling in place, to moving through space. The softer, intangible qualities of the city, through the temporal dimension of moments of human movement, have thereby been largely ignored.

This paper argues that the core of the problem hinges on exclusive thinking and practice within disciplinary silos, disconnected from the multi-layered, subjective experience of urban place through movement in space and time. This problem can be traced back to the conceptual approaches to urban mobility since the first industrial revolution, which broke away from subjective experience, into objectivist, rational conceptualisations of urban transport systems. The dominant focus on connectivity for the efficient movement of goods and services progressively excluded the multi-layered human experience of movement through space. The psycho-spiritual experience of dwelling in place hence succumbed to the frenzy of movement to connect finite activities and opportunities in the city.

The aim of this paper is to expound a critical interdisciplinary inquiry towards alternative thinking for urban inclusivity in public transport systems. This will be achieved through the following objectives:

\section{- A critical review of thinking and} approaches to urban transport and their influences on urban inclusivity.

- To comparatively analyse the principles of urban accessibility against the principles or approaches of humanistic inclusive urbanism.

- To critically analyse the contemporary conceptual approaches to urban development (public transport) in the city of Durban, South Africa.

- To propose an alternative, human-centred approach to urban mobility and accessibility towards inclusive urban transport.

\section{METHODOLOGY}

A mixed methods approach, underpinned by a pragmatist philosophy, defines the qualitative study. Secondary data will be collected analysed through a literature review of systems and conceptual approaches to urban transport and their influences on humanistic urban inclusivity. Primary data used was in the form of visual and graphic analysis of the contemporary conceptual approaches to urban development and public transport in the city of Durban, South Africa.

\section{CONCEPTUAL \\ FRAMEWORK: CRITICAL APPROACHES TO MOVEMENT IN PLACE AND TIME TO ENHANCE COMPLEXITY OF HUMAN URBAN EXPERIENCE.}

The paper argues that while social justice theories promulgate equitable access, rights and liberties, these are compromised by a lack of spatial justice in modern cities. It is argued that the predominant motor-vehicle modes of urban transport have severely impacted the social / anthropological right to the city (Lefebvre 1996) at a spatial scale, through spatial barriers that compromise the psychological and spiritual experience of the city. Soja (2009) affirms that critical spatial thinking involves the ontological spatiality of being, the social production of spatiality and the socio-spatial dialectic.

At an ontological level, the concept of being and dwelling in space in time defines a psycho-spiritual spatial quality that vitalises and transforms space into place. The city had traditionally existed as a place of layered complexity that provided much more than access to various tangible goods and amenities; it was a place of conscious and subconscious dwelling than would invigorate - a psycho-spiritually stimulating gallery, a rich resource of incidental awareness and engagement. This engagement would play out as a constant interaction between one's consciousness, with the collective spirit of place. The complexity of urban planning and the complexity of urban detail in architecture and landscaping formed and was formed by the vital psycho-spiritual interactions, at an ontological level of being that would define the socio-spatial dialectics in the city. These socio-spatial dialectics reveal a vital symbiosis between the spatial and the social, whereby space defines social patterns in as much as social activity defines space. Soja's notion of the social production of spatiality affirms that space is socially produced and can therefore transform in response to changing social patterns. Essentially, being in place and time catalyses various psycho-spiritual 
and socio-spatial interactions that determine the choices people make in navigating and dwelling in the city.

Complexity in Placemaking at an ontological realm of being and dwelling is expounded in the various works of architect / mathematician, Christopher Alexander. The genius of Alexander, in the context of urban complexity, is attributed to an ability to combine scientific methodology with a humanistic and artistic approach to design. In The Nature of Order (Alexander 2001), he interrogated a process of design that could respond to the indeterminate choices that people make in the real world, while his essay, A City is not a Tree (Alexander 1966), synthesised his mathematical faculty with his humanistic design approach to propose a complex way of interpreting urban place by understanding various complex overlaps whereby various indeterminate sociospatial interactions defined urban place.

Given that the general spatial pattern of the modern city is formed by a combination of buildings, as solids, and streets as the predominant voids, it is critically important to analyse the role of the street in socio-spatial activation. Reference is, therefore, made to Pritzker Award winning architect, Balkrishna Doshi, in his approach to Complexity in Street Design, exemplified by his statement:

“... the street must assume a unique identity on human scale with spaces for group activities" (Doshi 1988).

\section{CRITICAL ANALYSIS OF URBAN MOBILITY IN THE CITY OF DURBAN}

The current patterns of urban movement in Durban reveals human psycho-spiritual alienation at different scales, by favouring the access of motor vehicles in urban spaces rather than the human experience of the city. While spatial barriers are generally referred to as fixed elements in urban design, it is argued that motor vehicles themselves form moving edges that sever the street from human participation. A figure ground analysis of a modern city such as Durban, clearly illustrates the proportional relationship of built form to open space - streets are the dominant open space system of the city; however, they serve as mere conduits and points of connection via motorized transport. The number of people moved per "engine" exacerbates the problem. When and how did this condition emanate?

\subsection{THE EVOLUTION OF URBAN MOBILITY IN DURBAN}

The streets of Durban had been laid out since the early British establishment of the city. The modes of transport, primarily horse-drawn cart, defined the street widths prevalent today. Non-motorised modes of transport, including horse-drawn trams (Fig 1), afforded a complexity of the street as open space, largely due to the pace of vehicle movement, allowing for simultaneous pedestrian and vehicle movement pedestrians, carts, rickshaws, and trams shared the street in seeming harmony. This was complemented by architectural detailing that fostered active edge engagement at human scale, in the form of arcades.

\section{Fig 1: Complexity of the Street as Public Open Space}

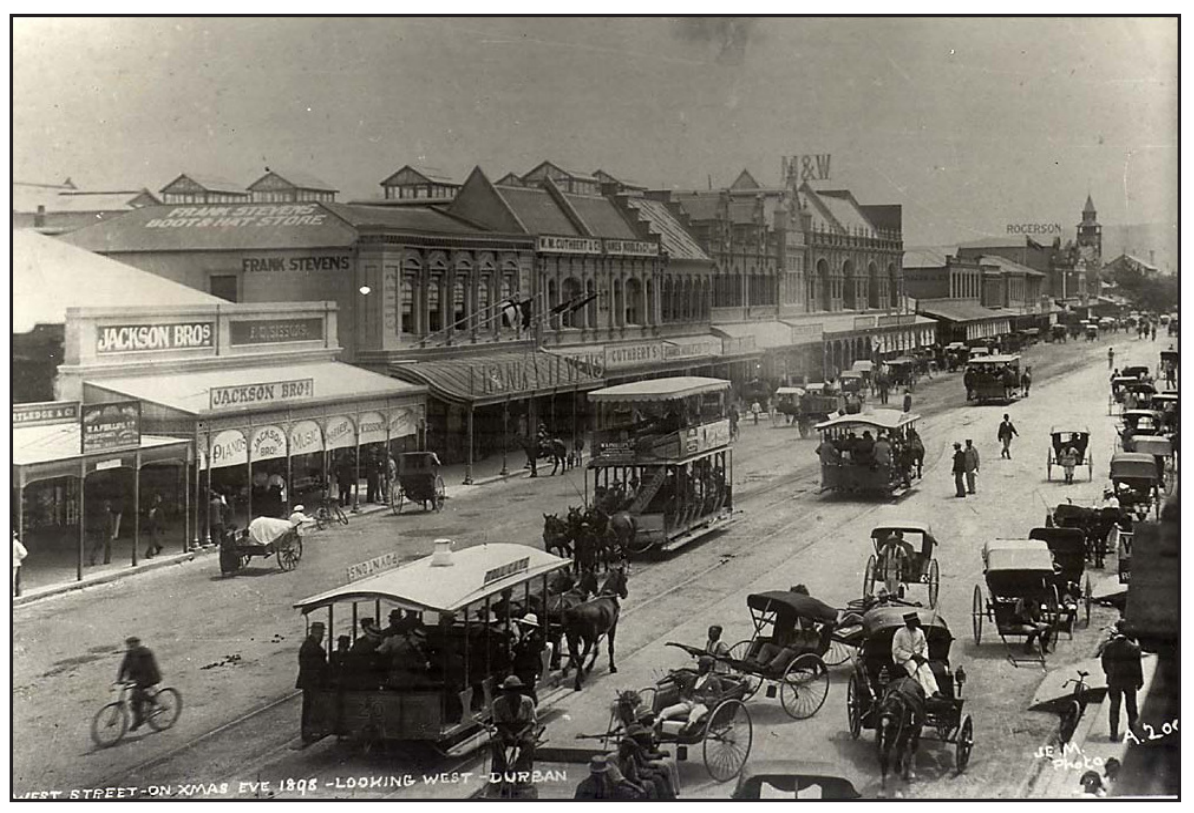

(Accessed Online: http://www.fad.co.za/Resources/transport/horse_tram2.jpg - 1898

Another important quality of the street as open space would play out in the Grey Street district, whereby the street would transform into market, such as the "squatter market" (Fig 2). During this early colonial period, the city streets expressed layered complexity, primarily due to the non-motorised forms of transport, thereby contributing to the unique identity of the street as public place for group activities. 
Fig 2: The Squatter Market (Rosenberg et al 2013)

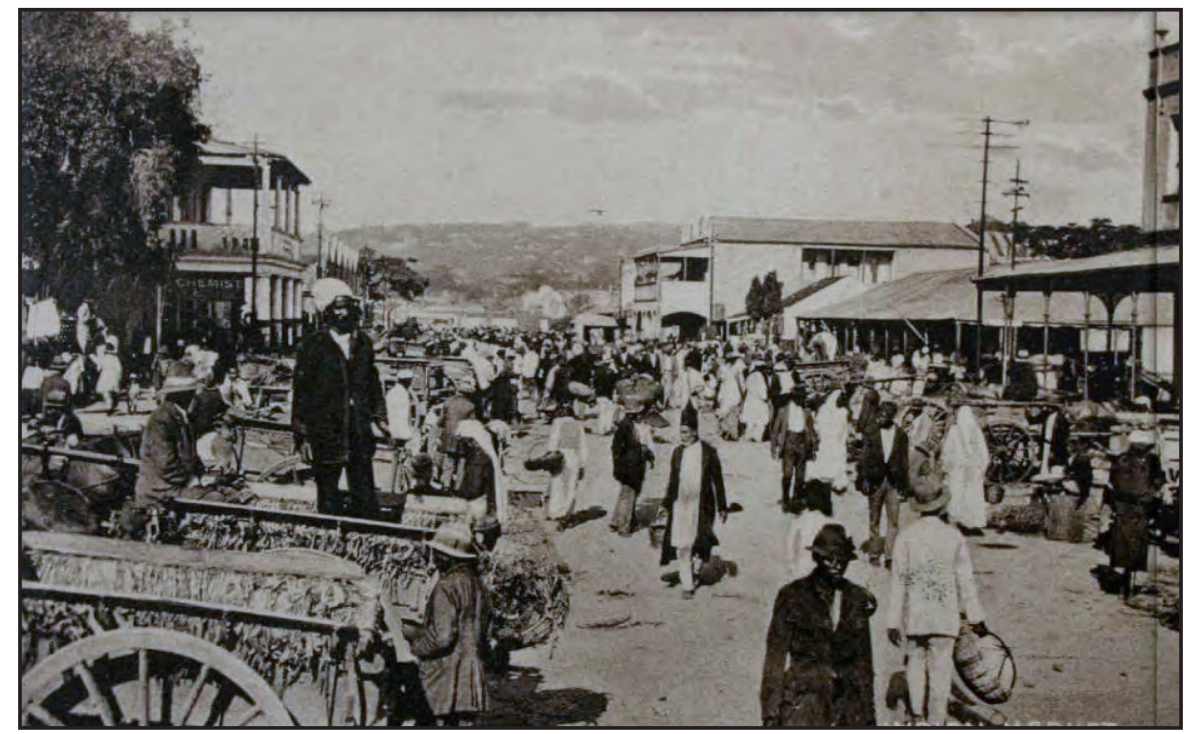

This quality would, however, change upon the advent of the motor vehicle. The increasing pace of the motorised vehicle would correspondingly reorder pedestrian movement patterns, redefine the socio-spatial dynamics, eventually resulting in parallel movement systems whereby vehicles would dominate the street, cutting off human accessibility (Fig $3 a \& b)$.

Fig 3a: Indicative Section through Grey Street illustrating the dominance of motor vehicles (Author).

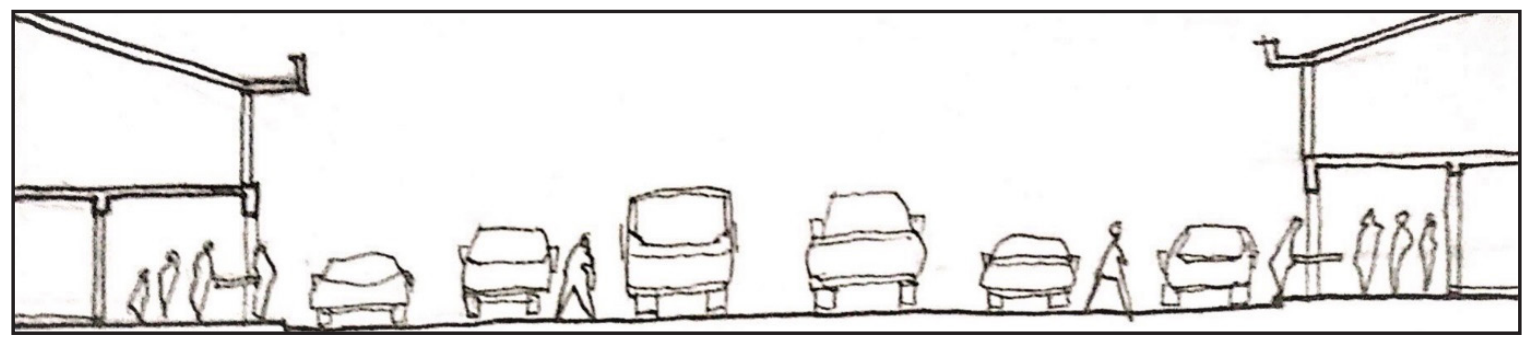

Fig 3b: Indicative Partial Plan of Grey Street illustrating the dominance of motor vehicles (Author)

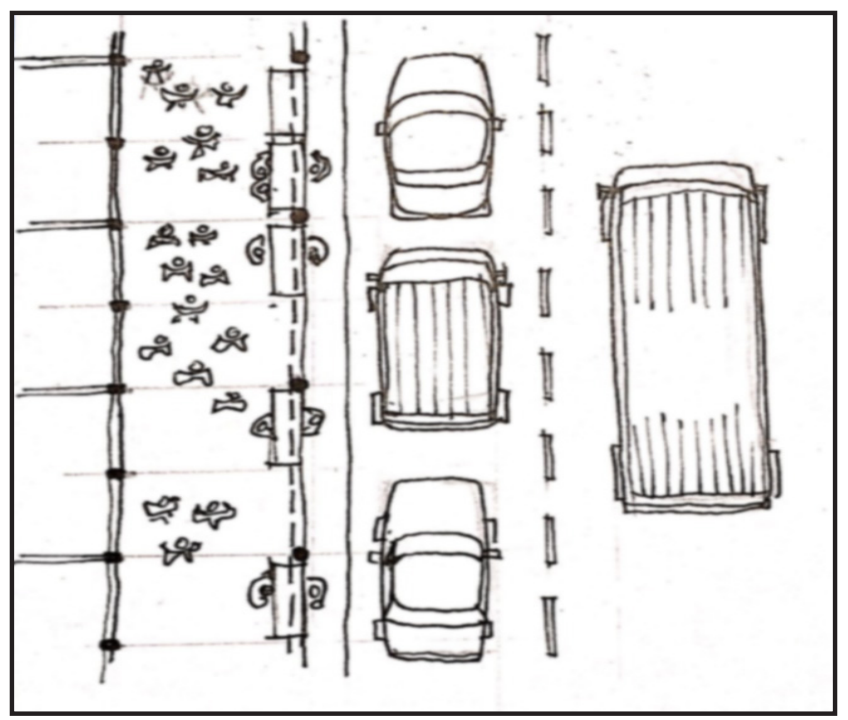

This problem intensified during the post-apartheid period due to an increase in the population of persons accessing the city daily, seeking opportunities that were previously inaccessible. Consequently, the increased pressure on the urban transport system by motor vehicles would further diminish the street as a once layered place for human experience (Fig 4). 


\section{Fig 4: Disconnection of the street as interactive place (Author)}

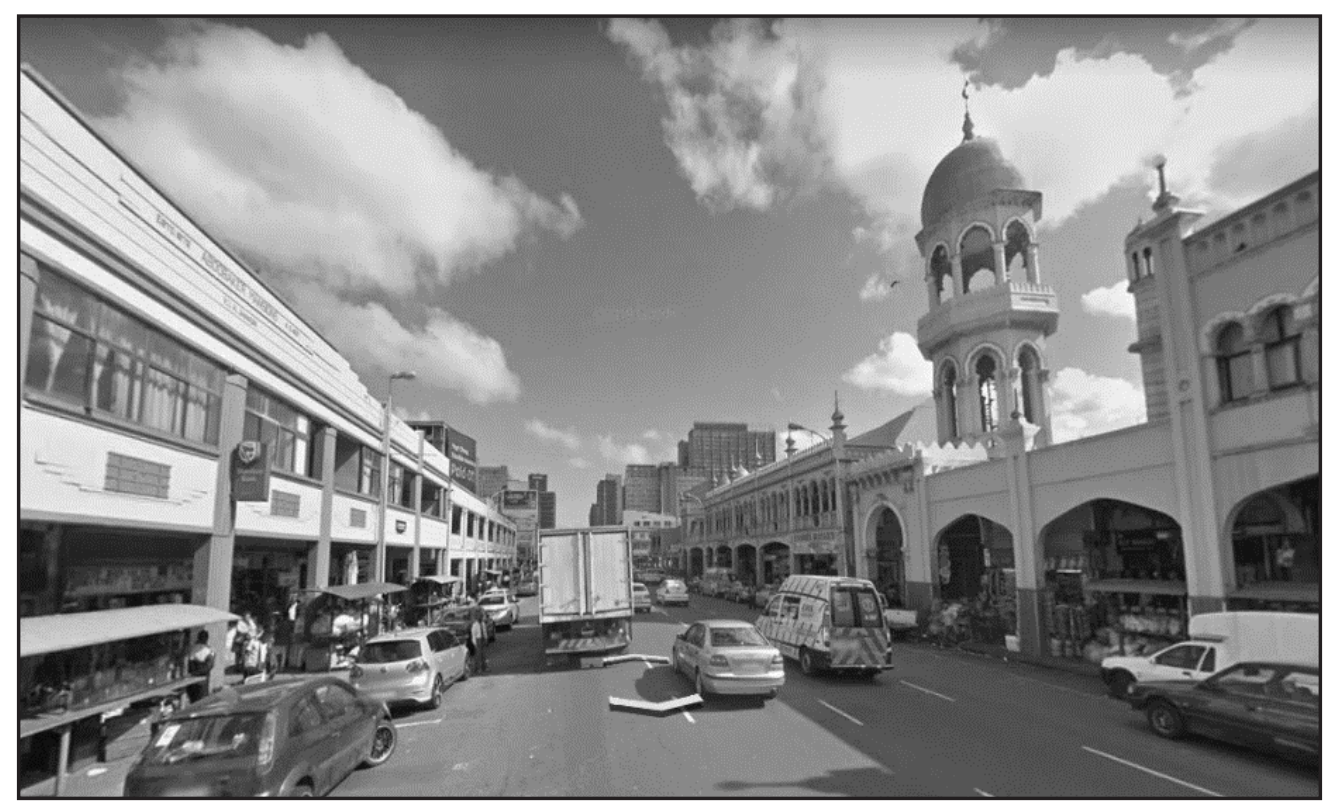

The advent of minibus taxis and the concurrent relative decline of the rail and bus system, led to a change in commuter preference; the minibus taxi provided affordable and accessible transport at various places in the city centre. While convenient, a resultant problem arose as the minibus taxi would translate into a fewer number of people being moved per engine, as opposed to other modes of public transport such as trains and buses. Another challenge was that minibus taxis would stop anywhere and everywhere, often to pick up a single passenger, expressing street edges as "moving walls" of minibuses (Figs 5\&6). The commuter convenience, provided by the minibus taxi, would also reduce the need to walk any reasonable distance between points of access / taxi stops. The ecological and wellness impact of this condition, in the context of healthy liveable cities, requires further study.

\section{Fig 5: Minibus Taxis as "moving walls" (Author)}

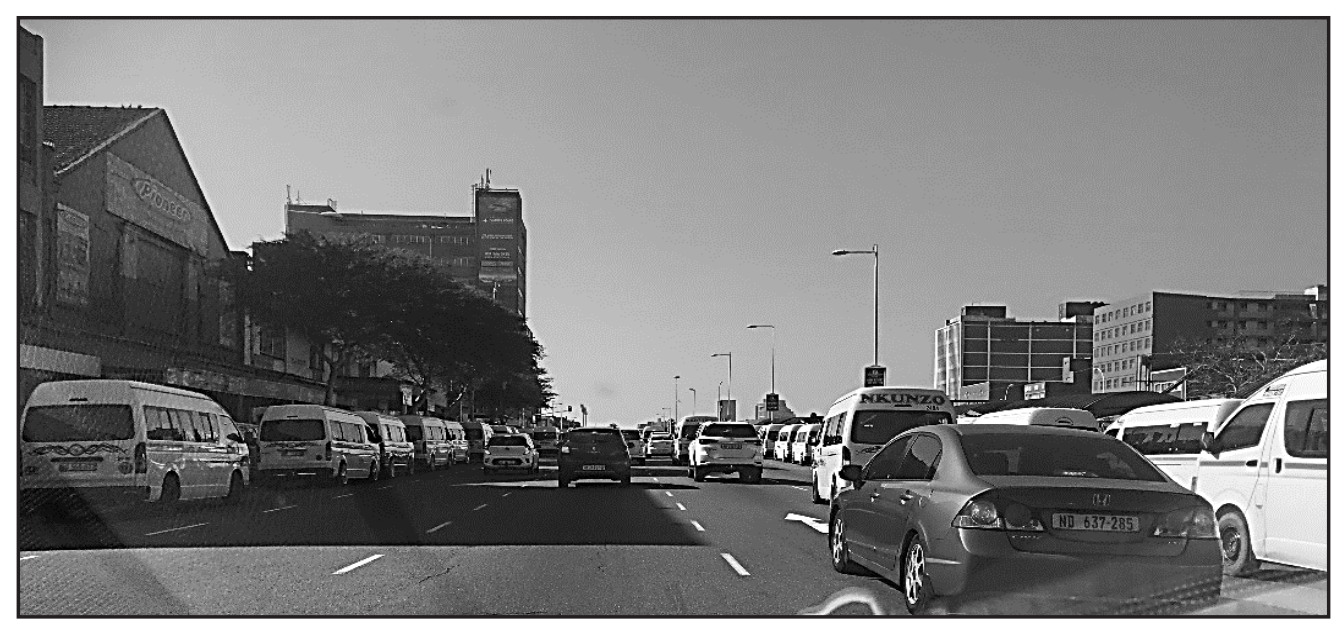

Recent initiatives to revitalise the city to promote healthy live, work and play spaces, resulted in the development of the Integrated Development Plan (IDP) and the Local Area Plan (LAP). An important feature of these plans was the notion of integrated transport systems, complemented by the walkable city concept, that could promote more efficient socio-spatial interaction. Some of the key spatial principles of the LAP were: a Connected City; Walkable City; Land Use Intensity - an Integrated and Inclusive City; and Realising the Potential. Of these, the walkable city concept relates most closely to the context of this paper.

The promotion of pedestrian and cycling streets and carefully considered nodes for public transport, integrated into densified local neighbourhood centres, fundament on the concept of walkable cities, could contribute to revitalisation towards an inclusive city. However, while the proposals presented in the IDP and LAP express conceptual thinking towards accessible urban precincts and integrated transport systems, promoting non-motorised modes, the city could benefit from a study of the "pockets" of inclusive urban place that do exist in the city, from which lessons could be learned. 
The Grey Street / Warwick Junction precinct has been analysed in the works of Luckan (2014a-b, 2015 \& 2018) and his current work on inclusive cities, that reveal various transformations of space into place through socio-spatial interaction. These works explain how lost and dead spaces are revitalised through the social production of space, the socio-spatial dialectic and the ontological spatiality of being. Some of the key concepts that run through the works include, the social appropriation of space, spatial recycling, socio-spatial activation, indeterminancy, spatial layering, incidental urbanism and conscious dwelling in place. While these works highlight the vitality of the mentioned urban precincts and the activation of edges and nodes, there is also an implicit exposure of the street as an inhibitor of socio-spatial urban interaction. Whereas the current LAP proposes walkability and densification of urban neighbourhoods, the interventions in the Warwick / Grey Street precincts often translated into the adaptive reuse of lost spaces and the addition of links via overhead activated pedestrian bridges. Essentially, the street had to be raised above the motor vehicle-dominant roads beneath to allow for the movement of people in the city (Fig 6).

\section{Fig 6: Link bridges as raised streets (Author)}

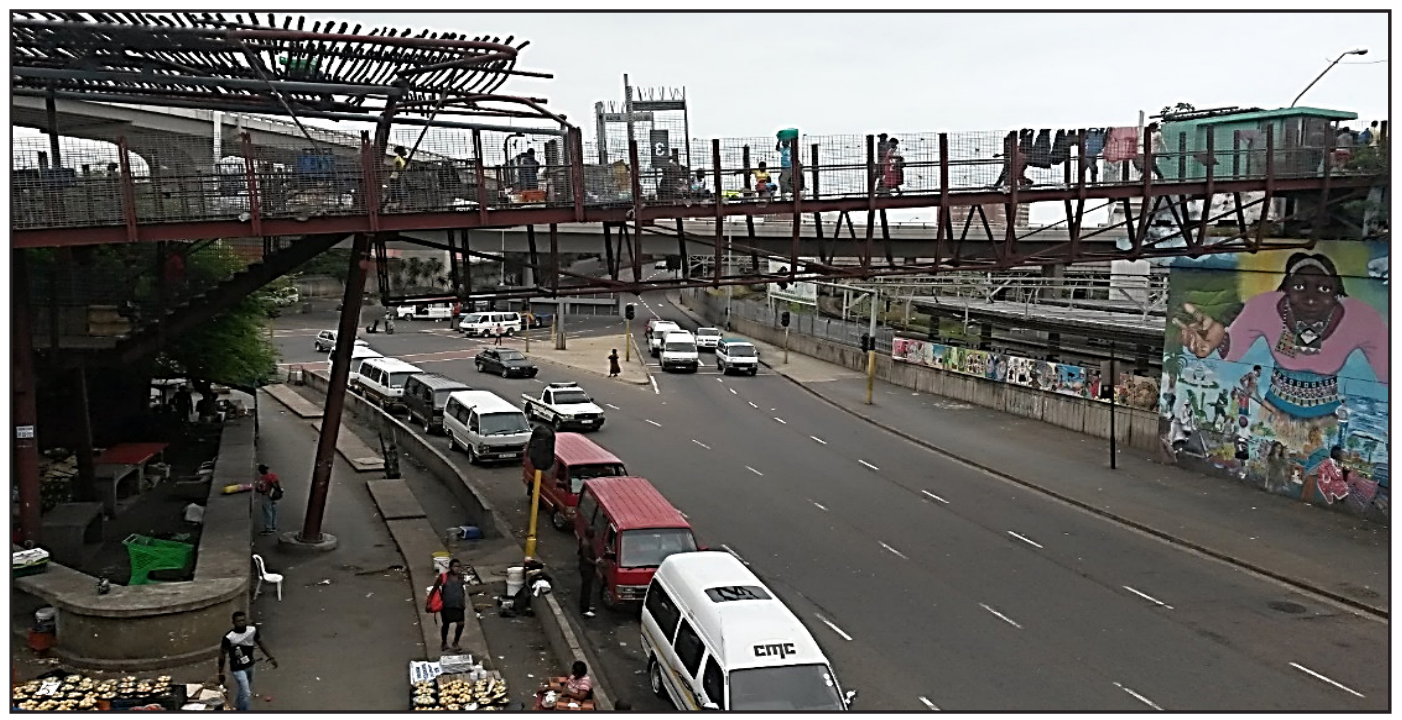

\section{FINDINGS AND PROPOSITION}

The findings of the research revealed that the inherent problems of hostile urban environments could be attributed to a disconnection of thinking and practice from the humanistic layers of urban place. Reliance on objectivist methods perpetuated the alienation of people form the urban open space system, dominated by the motor vehicle; ironically by design.

This paper challenged the objectivists modes of urban public transport design, by arguing that the human subjective experience of the city be given much more consideration in thinking and practice. The ontological spatiality of being / psycho-spiritual dwelling in place through time requires deep consideration to focus on the human as central to urban movement. This requires a shift beyond the current definitions of mobility and accessibility.

Urban accessibility and the right to the city cannot merely be considered a utilitarian pursuit; the intertextual, psycho-spiritual, experience of the place itself has profound impact on urban vitality and therefore requires deep consideration and engagement. Thinking about inclusive urban movement necessitates the inclusion of the intangible, qualitative and layered subjective experiences of people through space and time. Urban vitality is dependent on such human movement through space and time, to be able to create a quality of placeness.

This would require an ethical shift in thinking and practice towards public transport infrastructure that can complement the layered complexities of humanistic urban experience, dwelling and being. Interdisciplinary / inter-experiential / participatory approaches in transport design are required to achieve inclusive urban movement. The design of urban transport systems would therefore require the integration of multiple intelligences across disciplinary domains, bridging the divides between the humanities, arts, engineering and technology. This kind of interdisciplinary collaboration, however, would require the inclusion of different methodologies for a comprehensive response to inclusive urban transport. Quantitative and empirical data would therefore not be sufficient alone; the perceptual interpretation of people moving through various moments in time would be vital to inclusive urban movement. Accordingly, the social production of space and the socio-spatial dialectic would be exponentially enhanced by the layered and variably temporal psycho-spiritual experience - the ontology of being - in the city through progressive urban movement. 


\section{REFERENCES}

Alexander C. (1966). A City is Not a Tree. Design. London Council of Industrial Design. 206: pp 1-17.

Alexander, C. (2001). The Nature of Order, The Phenomenon of Life; Center for Environmental Structure. Volume 1.

Berkeley, CA, USA.

Doshi, B.V. in Khan, H. Ed. (1988).

Aranya Township, Indore. Mimar 28: Architecture in Development. Singapore: Concept Media Ltd.

Lefebvre, H. (1996). Writings on cities (E. Kofman \& E. Lebas, Trans.). Cambridge, MA: Blackwell.

Luckan, Y. (2014a). Analysis and perception: architectural pedagogy for environmental sustainability, EcoArchitecture Journal Vol.5, WIT Press 2014. pp 577-588.

Luckan, Y. (2014b). D’Urban resilience: The Warwick Junction Precinct. L'architettura delle città: The Journal of the Scientific Society Ludovico Quaroni. Vol. 3-4-5 / 2014: The City in Evolutionary Age: pp 165 -194.

Luckan, Y. (2015). The Human City: People, Place and Time as critical determinants of urban quality. Tsinghua University, Urban Design Journal. Vol. 2/2015: pp $048-063$

Luckan, Y. (2018). City to Waterfront: A Metaphoric Journey through Space and Time. L'ADC L'architettura delle città. The Journal of the Scientific Society Ludovico Quaroni. L'ADC UNESCO Series \#4: Durban A Cogent African City: pp $61-66$.

OECD (2020), Improving Transport Planning for Accessible Cities, OECD Urban Studies, OECD Publishing, Paris, https://doi.org/10.1787/fcb2eae0-en.

Soja, E.W. (2009) The City and Spatial Justice. [" La ville et la justice spatiale », traduction : Sophie Didier, Frédéric Dufaux], justice spatiale | spatial justice | n01 Septembre | September 2009: pp $1-5$. 
Notes 